\title{
A vueltas con el psicologismo. Heliogábalo y la cura de la homosexualidad para el sujeto histórico
}

\author{
Chrístopher Recio Sobrino \\ Universidad de Oviedo \\ alabama915@hotmail.com
}

\begin{abstract}
Resumen:
la necesidad de la educación en bioética nos ha llevado a enunciar la defensa de una nueva interpretación psicologista del sujeto histórico 'Heliogábalo', ayudándonos de las teorías sobre la reconducción del gusto, hallaremos a un nuevo individuo que dará cuenta del porqué de sus actos.
\end{abstract}

Palabras clave: sujeto histórico; homosexualidad; educación; humanidad

\section{New with psychologism elagabalus and cure of homosexuality for historical subject}

\begin{abstract}
:
the need for education in bioethics has led us to enunciate defense a new psychologistic interpretation of the historical person 'Elagabalus', helping us the theories on renewal of taste, we find a new guy who will realize why their acts.
\end{abstract}

Key Words: historical person; homosexuality; education; humanity

\section{Referencia normalizada:}

Recio Sobrino, C. (2014): A vueltas con el psicologismo. Heliogábalo y la cura de la homosexualidad para el sujero histórico. Historia y Comunicación Social. Vol. 19. Núm. Especial Marzo. Págs. 401-407.

Summary: 1. Introducción. 2. Útiles para una re-interpretación. 3. Reforma. 4. Conclusiones

\section{Introducción}

La Historia, entendida como ente objetivo, nunca ha encumbrado a nadie; los estudiosos del pasado sí. De tal modo que personajes fatídicos o heroicos para la humanidad, han recibido esa adjetivación en cuanto sus actos o pensamientos concuerdan con muchos de los sentimientos encontrados por el erudito. Así entendido, parece que la historia de la Historia es descrita subjetivamente, lo cual puede llevar a una injusta descripción del personaje a estudiar, ya sea por una deficitaria narración de su existencia o por una excesiva adulación. 
Personajes diversos, y cuya existencia pasada es veraz, como por ejemplo, Julio Cesar, Napoleón, Hitler, Gandhi, etc., no solo han hallado su puesto en la Historia, ya sea para bien o para mal, pero ante todo: recordadas sus acciones con un fin evitativista o emulador futuro claro, lo cual no quiere decir que la Historia sea teleológica. No obstante los personajes mencionados han sido estudiados por numerosos individuos, expuestas sus bienaventuras y desventuras, estudiados únicamente a través de los restos arqueológicos o historiográficos así como interpretados psicológicamente. En resumen: ríos de tinta han corrido para cada uno de ellos desde diversas perspectivas de análisis; lo mismo no puede decirse en el caso de el emperador romano Marco Aurelio Antonio Augusto (203-222 d.C), más conocido como Heliogábalo.

La poca fiabilidad de la información aportada por los historiadores sobre este personaje es, realmente, fruto de la exigua fiabilidad de las fuentes. Parece necesaria, hacer, una arqueología fenomenológica de los contextos geográficos, religiosos, políticos y psicológicos, que subyugó al emperador a ese metafórico ostracismo histórico que hubo de sufrir por consecuencia de la migración de un mundo que conocía a otro que le era lejano, pero no del todo desconocido, es decir: su vuelta a Roma ya no como un sacerdote de una religión mistérica sino como emperador, eso sí: un Emperador Sirio. Un título al que no llegó a profesar la devoción requerida; su primer cometido era el sacerdocio, las ocupaciones que posteriormente devinieran de su cargo eran, en cierto modo, superfluas.

Dicha información, como otra mucha, es el resultado de las lecturas contemporáneas del emperador, cuyos autores son: Herodiano (178 d.C-252d.C) y Dion Casio (135 d.C-235 d.C?). En ellos observamos dos narraciones de una época común pero diferente en cuanto a rango de cada uno, siendo el primero un liberto historiador y el segundo senador, cónsul, etcétera. Sin embargo la crítica hacia el emperador suele ser producto de la aberración por su personalidad o producto de lo cómico de su sensibilidad, creyéndolo inepto para el cargo que ocupaba. Del mismo modo el odio levantado por Heliogábalo no influía únicamente a políticos o estudiosos. Influyó a todo Roma por sus decisiones religiosas impropias de un Pontifex Maximus, llegando a sustituir a Jupiter por una deidad inferior y bárbara: El-Gabal, rebautizándolo como Deus Sol Invictus. Y al tratarse de una violenta religión de rituales no lógicos, la sangre derramada sobre el Tíber tiñó la ciudad de rojo.

La cuestión subyacente que deseamos plantear no es qué intereses hubo por parte de la gran emperatriz siria para embestir a un sacerdote del Sol como emperador, ni desenmascarar las atrocidades que fueron consideradas bromas, las extravagancias o la actitud azafránea de las noches en vela; lo que hemos de plantearnos es porqué no existe otro tipo de historia sobre el personaje en cuestión y, habiendo posibilidad de una narración alternativa, mediante qué fundamentos y materiales llevarlo a cabo. La primera cuestión es referida por diversos autores como lo espantoso y humillante de la actitud cuasi-pornográfica del emperador, dado el hecho de que las relaciones homosexuales entre hombres pudieran aceptarse en la época siempre y cuando el amo tuviera el papel dominante y el esclavo el sumiso. Lo imperdonable hubo de ser la inversión de la norma nada más y nada menos del propio emperador. 


\section{2. Útiles para una re-interpretación}

La propuesta de una nueva lectura sobre el emperador romano es, admitiéndose la autocrítica, psicologista; valiéndonos de los aires de liberalidad social del siglo XX y XXI, afrontaremos la dicha mediante un proceso harto de provocación, a saber: la cura de la homosexualidad. Efectivamente los estudios sobre la "sanación" de la homosexualidad serán los aquí utilizados no sin aviso claro: nos valdremos del método explicado por los autores para la reconstrucción existencial del emperador, pese a que no subscribamos ni apoyemos esas teorías marchitas. En tal caso pudiera hablarse de una reconducción del gusto de todos aquellos homosexuales no gays (de todos aquellos individuos que siendo homosexuales no se encuentran en sintonía con el modo de vida gay, ya que ellos mismos la asocian con algo negativo, y sufren).

Las teorías de la sanación de la orientación sexual emergen en la década de los años 20 y 30 del Siglo XX, a raíz de los estudios psicoanalíticos de Freud, el cual al final de su vida veía esa "cura" como un proceso interminable, una constante represión del yo. Lo que los autores modernos indican es que sí, es cierto que la "cura" completa no existe debido a que, como todo proceso terapéutico similar al alcoholismo, nunca desaparecerá ese deseo por el mismo sexo. Lo negativo de los estudios es aquello en lo que se basan: trabajo de campo de psicólogos con sus propios pacientes que se ven envueltos en una vorágine de autodestrucción que puede llevar al suicidio; de las afirmaciones de los pacientes sobre el rechazo que sienten por el mundo gay al no aceptarse ellos mismos. De ahí que la psicología moderna no ofrezca más alternativa que el proceso de aceptación, pese a que existe la otra vertiente, más desconocida y compleja: la sanación.

En cualquier caso, por muy discutible que sea el tema, lo que deseamos de los señores como Joseph Nicolosi, Socárides \& CIA., es el método que utilizan para llegar a proferir tales afiermaciones:

- En primer lugar se rastrean los recuerdos del paciente para averiguar qué hechos son los que han generado tal desvirtuación del gusto. No indagan en el ambiente escolar, puesto que pese a lo duro que puedan resultar las relaciones siendo homosexual en esa época vital, resulta natural que el mundo pueda ser cruel. El problema reside en las relaciones que pueda tener con sus progenitores, es decir: si existieron relaciones de afecto débiles entre un hijo o hija con la madre o con el padre.

- Habiendo encontrado la génesis en una de las débiles relaciones por causa de la madre o el padre, se procesan los datos y se analizan los deslices vitales a la luz de esa nueva información. De tal manera que, por ejemplo, si ha existido una relación de de padre-hijo distante, de maltrato físico y psicológico, de favorecimiento a hermanos sobre un individuo (en este caso: chico), así como la amistad que mantiene con la madre, el chico pasa a tener relaciones homosexuales de manera casual, que le atraen, le divierten, le dan placer y un 
aparente sentido de cariño pero que, en el fondo, no le satisface y repudia, ya que lo que busca es el cariño de un padre.

- Finalmente se llega al proceso pragmático. El tratamiento requiere, como en la terapia contra el alcoholismo, de un muro de amigos y familiares que respalden esa decisión de "curar" la homosexualidad. Así pues, el individuo tendrá varias amistades: los familiares, los amigos homosexuales que saben de su problema y le apoyan, los amigos heterosexuales que saben de su problema y le apoyan, y los amigos homosexuales que no saben nada sobre su problema pero igualmente le apoyan. Así mismo se le aconseja romper con todo tipo de relación homosexual, ya que tras el tratamiento los recuperará, y comenzar a tener relaciones masculinas sanas con hombres heterosexuales que no sepan nada sobre su problema. Del mismo modo necesitará de la ayuda de un mentor, un individuo fuerte y masculino que le guíe hacia la liberación de aquellos deseos que no le agradan de sí mismo.

De manera resumida ese es el proceso a seguir para la reconducción de la homosexualidad. Los pasos finales resultan obvios: recomponer la relación del hijo y el padre, y formar una familia, si es que ese era su deseo.

Ahora bien, de todo lo descrito ¿qué es aquello que necesitamos para la nueva interpretación del sujeto histórico 'Heliogábalo'? La idea central que fomenta los útiles para ello es: (1) Presuponer la transexualidad de Heliogábalo, (2) presuponer unas circunstancias ambientales que, de ser hoy, afectarían traumáticamente a todos aquellos infantes que hubieran vivido lo que el emperador hubo de vivir, (3) guiarnos por la sensibilidad, las emociones para explicar una forma de vida de la cual no se tiene más que restos del pasado, y no entrevistas grabadas.

\section{Reforma}

Admitiendo la veracidad de todo lo indicado en el libro Heliogábalo o el anarquista coronado, de Antonin Artaud, repararemos en que el hecho que más pudo influenciar a la hora configurarse la personalidad del emperador fue el ambiental; habiendo sido coronado sacerdote del Sol con cinco años, sus obligaciones como responsable de la devoción a un aerolito negro en forma de falo que había provenido de los cielos, le destinó a visionar, sin quererlo, las fiestas equinocciales de su religión en la ciudad de Emesa, lugar en el cual existía un abrupto socavón en forma de vagina, alrededor del cual se bailaba desenfrenadamente, se comía vorazmente y se mutilaban frívolamente. Los hombres se convertían en mujeres y las mujeres se convertían en hombres, penetrando y desgarrando los rectos de los varones con juguetes fálicos de madera que les llegaban a quitar la vida. Al acabar la fiesta la sangre y las eyaculaciones, los cadáveres, así como la comida y animales muertos debían ser arrojados al foso, al que el sacerdote del Sol habría de bajar una vez al año, no se sabe porqué motivo. 
Como sacerdote de tal religión mistérica, Heliogábalo, por aquel entonces conocido como Basiano, disfrutaba de los dones de sus fieles más dotados. Y así hubiera seguido siendo si no hubiera acaecido la muerte de Caracalla (188 d.C-217d.C), lo que llevó a las tropas de Heliogábalo (astutamente gobernadas por Julia Mesa -165 d.C- 224d.C-, abuela del emperador y cuñada de Julia Domma -170d.C-217d.C-), a enfrentarse a las tropas del usurpador al trono: Macrino (165 d.C- 218d.C). Vencido el usurpador, Basiano fue embestido emperador en Siria, cambió su nombre por el de Marco Aurelio Antonio Augusto y comenzó su viaje hasta Roma. Allí sorprendió doblemente: por sus delicados gustos aromáticos y vestuario, por su cuerpo afeminado y dulce voz, al igual que por su gusto desmesurado por los hombres, su devoción religiosa que en última instancia provocó su fin, los sangrientos ritos, los desmesurados castigos y las nunca bien admitidas bromas.

Ya que el libertinaje más sádico del comportamiento del emperador llegó a inspirar a Sade. ¿Cómo es posible, entonces, ofrecer otra óptica si son precisamente los escritos del ilustrado francés el vivo ejemplo de la crítica a la propia Ilustración: análisis extremadamente objetivo, falto de humanidad de perversiones cumplidas? Guiándose en uno de los principios clave en el análisis histórico: rechazar prejuicios y evitar la influencia de todo tipo de creencias para, acto seguido intervenir con el análisis emociona, más humano que ofrecemos. De tal modo lo que obtendríamos, mediante el proceso arqueológico-fenomenológico, es la generalización de los sujetos que intervienen en la época, llegando a tener nada más y nada menos que un ser humano, proclive a la sugestionabilidad de un modo de vida repetitivo e insano. Un ser humano que es un niño que ha confundido la realidad pues lo que ve es lo que él considera como real y correcto, todo lo que no siga el patrón de la perversión es para él la perversión en sí, algo que le puede resultar peligroso y que, de no combatirlo, puede acabar con el mundo que conoce, lo cual resultar terrorífico, desalentador. Por ello resulta natural el comportamiento que hubiera tenido en Roma; refiriéndonos a la religión y a los gustos sexuales, no a los castigos y las bromas. Su ambiente cultural era el de Emesa y con ello vivió hasta que fue asesinado por los mismos que le convirtieron en emperador, el ejército.

\section{Conclusiones}

Sí, como bien indicamos en otros discursos, la educación del emperador hubiera sido distinta su historia hubiera sido diferente. Pero como condicionar una hipótesis sobre la estructura vital de alguien para concluir cualesquiera aseveraciones es falaz, no queda más remedio que apartar de nuestro camino hipótesis y contra-hipótesis que nos facilitarían el camino. Lo expuesto aquí es una breve reivindicación no ya del emperador romano, Heliogábalo, sino el interés por historias psicologistas de sujetos, puesto que ha de tratarse de un individuo y no de varios, estaríamos hablando entonces de sociología. 
El estudio psicologista se construiría del modo que sigue: un interés por un sujeto $\mathrm{x}$, un interés por un tema relacionado con algún aspecto del personaje, y excluir, finalmente, de ese tema de interés todo aquello que no sirva como útiles para su estudio, esto es: en el breve studio que nosotros hemos hecho hemos excluido la "historia de las teorías de la reconducción del gusto" así como posibles individuos entrevistados en esos estudios que pudieran tapar el interés por el sujeto histórico, al mismo tiempo que hayan de excluirse cualquier opinión nociva producto de las creencias singulares.

El tema que nos ha tratado era Heliogábalo y su escasa bibliografía, debido a los prejuicios y el silencio que se mantuvo tras su muerte ya que pareció no aportar nada a la historia. Lo cual es un error ya que lo aportado son sufrimientos de las personas y perversiones tabú que hoy día adquieren relevancia y son alabadas. Ello demuestra que el pasado por muy turbio que haya sido, debido a un sujeto, no ha de ser olvidado, ya que hoy se repiten los rituales de morbosidad, eso sí: no a la luz del día, ni al aire libre.

Aportar el conocimiento de los hechos degenerados como una posible asignatura de secundaria o universitaria es una de nuestras luchas, ya que creemos que el estudio adecuado de las mismas será beneficioso, ya que su fin será el de poder evitarlas. Así como el de fomentar la ética en las carreras con el fin de no perder esos restos emocionales que residen aún en el ser humano y no perjudicar a los futuros estudiosos con preferencias por las que el erudito haya optado; unos estudios sin engaños y humanos.

\section{Bibliografía:}

\subsection{Libros:}

CUMONT, FRANZ (1987): Las religiones orientales y el paganismo romano. Akal. Madrid.

HERODIANO (2007): Historia del Imperio Romano. Gredos. Barcelona.

LOMBARD, JEAN (1950): La agonía. Bizancio. Madrid

RIRRIOLI, ARMANDO: De Julio Cesar a Heliogábalo. Vida íntima de varios emperadores romanos. Caro Raggio. Madrid.

\subsection{Artículos:}

CID LOPEZ, ROSA MARÍA (1993): Las emperatrices sirias y la religión solar. Una nueva valoración, en CARMEN BLÁZQUEZ PÉREZ \& CIA en Formas de difusión de las religiones antiguas. ARYS, Ediciones Clásicas. Madrid.

RODRÍGUEZ GERVÁS, MANUEL (1994): La vida de los emperadores infames Cómodo y Heliogábalo: a propósito de la Historia Augusta, en JAIME ALVAR \& CIA en Sexo, muerte y religión en el mundo Clásico. ARYS, Ediciones Clásicas. Madrid. 
RECIO SOBRINO, Chrístopher (2013): Ética y bioética como propuesta y cambio para el establecimiento de una educación «humana», en SIBI en VIII Congreso Mundial de Bioética.

URÍAS MARTÍNEZ, RAFAEL (1994): Transgresión sexual y transgresión religiosa en Heliogábalo, en JAIME ALVAR \& CIA en Sexo, muerte y religión en el mundo Clásico. ARYS, Ediciones Clásicas. Madrid.

5.3 Artículos en publicaciones web:

NICOLOSI, JOSEPH (1991): Terapia reparativa de la homosexualidad masculina. Un nuevo enfoque clínico.Disponible en: http://www.pfox.org/ebook_terapia_ reparativa_nicolosi.pdf

\section{El autor}

Chrístopher Recio Sobrino. Estudiante de Filosofía en la Facultad de Filosofía y Letras de la Universidad de Oviedo. Participación en 'Journée d'etude Lira: Monstres y monstruosités esthétiques et sociales contemporaines'en la Universidad de Rennes con la ponencia titulada Concepto y clasificación cinematográfica de monstruo y monstruosidad. El día Viernes 16 de Marzo del 2012. (Pendiente de publicación). Participación en el 'Círculo Hermenéutico: Seminario de Estética y Semiótica' en la Universidad de Oviedo con la ponencia REVERSVM SEXVS IMPERATORIS IN SPECULO: LA CRUELDAD DE LA ANDROGINIA. El día Miércoles 16 de Mayo del 2012. Participación en el 'VII CONGRESO MUNDIAL DE BIOÉTICA' con la comunicación Ética y bioética como propuesta y cambio para el establecimiento de una educación "humana", así como la publicación de dicha comunicación. El día Martes 14 de Mayo del 2013. 